\title{
Asymmetric competition and collection rates differentials: determinants of prices in international telephone service markets
}

\author{
Alberto Nucciarelli • Massimo Gastaldi • \\ Nathan Ghiron Levialdi
}

Accepted: 24 June 2009 / Published online: 8 July 2009

(C) The Author(s) 2009. This article is published with open access at Springerlink.com

\begin{abstract}
The paper investigates determinants of pricing in international telephone service markets. The analysis-focused on 24 worldwide national markets-shows the impact of several telecommunications-specific and macroeconomic variables on collection rate differentials and traffic imbalance between countries. An econometric model is aimed at performing quantitative analysis and providing support to future telecommunications policies.
\end{abstract}

Keywords Asymmetric competition - International telephony • Traffic imbalance

\section{Introduction}

In the last two decades, the increase of means for international communications has steadily impacted on the level of prices for fixed telephone services and the amount of international traffic as well [1,2]. As shown in Fig. 1 in 2007,

\footnotetext{
A. Nucciarelli $(\bowtie)$

Department of Industrial Engineering and Innovation Sciences,

Eindhoven University of Technology, Eindhoven, The Netherlands

e-mail: a.nucciarelli@tue.nl

M. Gastaldi

Department of Electrical and Information Engineering,

University of L'Aquila, L'Aquila, Italy

e-mail: massimo.gastaldi@univaq.it

N. G. Levialdi

Department of Firm Engineering,

University of Rome 'Tor Vergata', Rome, Italy

e-mail: levialdi@disp.uniroma2.it
} 


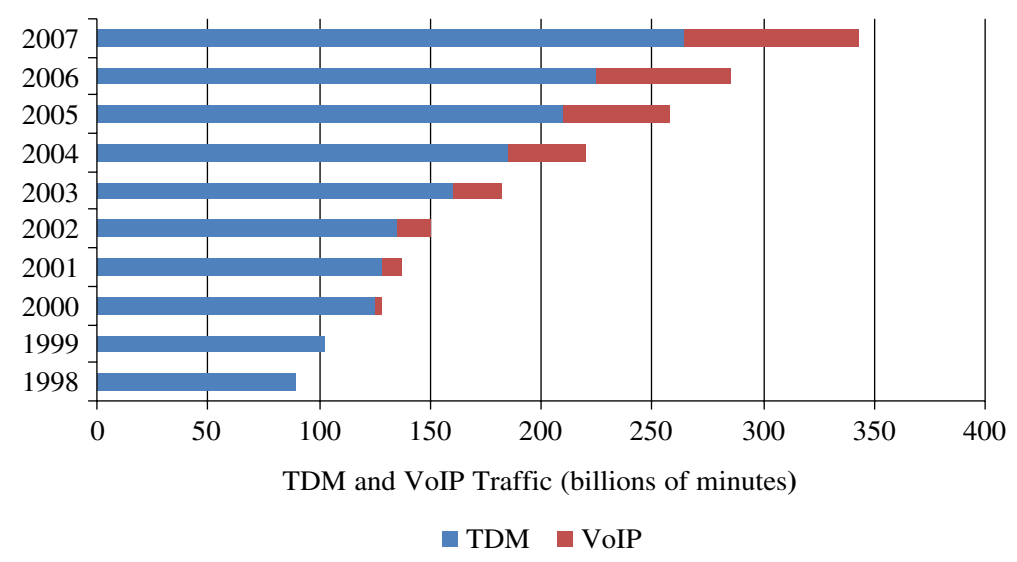

Fig. 1 International Call Volumes 1998-2007. Source: [3]

out of 343 billion minutes of international traffic, 77.7 billion minutes were carried as voice over IP (VoIP).

As reported by Telegeography [3], in 2007 traditional Time Division Multiplexed (TDM) experienced an annual growth of $10 \%$ while VoIP grew of about $28 \%$. Growth was particularly slow in Europe and North America. These are the two regions that generate $75 \%$ of the world's international traffic. Technological developments (e.g. digitalization of signals) and market deregulation (i.e. liberalization of access to incumbent's fixed lines) as well as changing social and economic behaviours (e.g. growing trade and touristic flows) have sustained this path [4-6]. There are many consequences of market liberalization and increased competition $[4,5,7,8]$ : (a) raising competitiveness made up of flourished and floundered alliances and joint-ventures among international carriers, high-tech firms and "network based" companies such as railways and power firms; (b) rapidly growing up of call volumes with high flexibility in pricing calls; and, (c) a radical change in the way of arranging bilateral market costs between countries in the long distance sector. As a consequence, for a long time Eastern European markets (e.g. Czech Republic, Hungary, and Poland) have been the "battlefields" where foreign incumbents and new carriers implemented their aggressive market polices. Incumbents tried to expand their strategic influence (through alliances and joint ventures) collecting new customers abroad and compensating for the loss of national market shares. New service providers progressively expanded their strategic influence through high-tech and investment-intensive projects increasing market shares especially in the long distance sector. They aimed at providing customers with a plenty of Value Added Services (VAS) and low priced hightech solutions. A leading result of such a challenging environment was the drastic reduction of pricing and the progressive disappearing of asymmetries between final prices in national and international telephone market. The possibility of reduced international call tariffs and changing market structure 
in many regions (i.e. Asia, Oceania and Africa) heavily contributed to raise call volumes. This trend compensated a particular slow growth of matured markets (e.g. Europe and North America). The radical changes in long distance sector (e.g. alliances and joint ventures among carriers, introduction of Internetbased communications solutions as VoIP and raise of call volumes) have deeply influenced the system carriers fix interconnection prices. As stated by Alleman et al. [9], companies founded "a reasonable basis for international telecommunications carrier pricing and settlements in the accounting rate system" (ARS). According to the ARS, "the two monopoly providers of international calls, one originating traffic and the other terminating traffic divided an artificial charge, labelled the accounting rate, one-half of which was the payment to the party which had a net imbalance of incoming traffic" [10]. More specifically, the accounting rate was bilaterally determined by negotiations between public telecommunications operators (PTOs) and it was "normally divided 50:50; half the accounting rate becomes the fee charged to terminate an incoming call, and called settlement rate" $[10] .{ }^{1}$ The settlement rate became a particular method of payment the PTOs applied to the imbalance of calls between the two carriers [9]. It looked like the best action to allow carriers compensating each other in case of differing demand levels among originating and terminating countries [11,12]. For some years, different authors have been asking themselves about the reliance of such a system [10,12-14]. International telecommunications community has gradually increased its attention towards the meaning of the ARS. It seems to be no further equitable and appropriate because of the growing payment imbalances, the increasing international telecommunications traffic and conflicts between carriers. Moreover, ARS does definitely not depend on the real costs of termination paid by PTOs in respective markets and this makes quite reasonable to think that accounting rate far exceeds the costs [4]. ${ }^{2}$ An intense debate comes from here. Alleman and Sorce [11] and Kelly [13] argue that long distance sector needs to be deeply reformed looking to transparency, cost-orientation and non-discrimination. In the same way, resale and call-back services "stimulate competition in a

\footnotetext{
${ }^{1}$ The international accounting rate system-developed in the 1930-was a system to determine "the division of revenue from international calls between originating, transit and terminating calls" [7]. For each international call from a country A to a country B, customers charged by the PTO an amount, named "collection charge". This was governed by the accounting rate, an "internal price between PTOs for a jointly-provided service" [15]. To complete a call, PTO B must agree to carry the call over its network. PTO is reimbursed for the cost of this service by a payment from PTO A. The payment is determined by the accounting rate; call the rate x. An agreement between the PTOs will specify that PTO A will pay PTO B an amount $\alpha \mathrm{B}$ x per minute of traffic for calls originating in country A and terminating in country B; for calls in the reverse direction, PTO B will pay PTO $\mathrm{A} \alpha \mathrm{A}$ x per minute of traffic (where $\alpha \mathrm{A}+\alpha \mathrm{B}=1$ ). (In most cases, the fractions $\alpha \mathrm{A}$ and $\alpha \mathrm{B}$ are both set to 0.5 i.e. the accounting rate is shared equally between the PTOs). The amount actually paid to the terminating operator (PTO B, in this case) is known as the settlement rate. PTO A covers the settlement payment by charging the caller in country A a collection rate for the total service provided [7].

${ }^{2}$ It is relevant, in this way, the impact of the technology over the reduction of costs for data \& voice transmission because of its influence over the decreasing of costs of high-tech devices and tariffs.
} 
non-competitive market, forcing the foreign carrier to negotiate a better settlement rate". Despite this evidence, technological progress, market liberalization and "the progressive reduction of costs in providing international services [... have] not be fully reflected in lower prices" [8].

A particular case of transparency violation and cost discrimination verifies where monopoly-structured and liberalised markets are connected, because the existence of imbalances for generated traffic has become evident. ${ }^{3}$ Such an effect can be mostly cast into the significant divergence of international telephone prices (collection rates) between carries-operating in liberalized markets - which continuously perceive collection rates reduction and carriers which are not induced by the stand-still natural monopoly to perceive efficiency and efficacy in providing services through cost reduction and decreasing rates. As stated by Madden and Savage [8], "countries that are efficient in generating outgoing traffic provide high-price countries with an increased settlement payment". Thereafter, they argue that rents transfer to monopoly countries are equivalent to "the difference between the settlement rate (the originating carrier's payment to access the foreign country's network) and the actual cost incurred by the foreign carrier in terminating the call". Along the same direction, Alleman et al. [9] state that "collection rate reductions by low price countries such as USA have increased their outgoing traffic relative to incoming traffic, and provided high price countries with increased settlement payments". The importance of worldwide asymmetric telecommunications markets relies on a great interest in studying flexible and affordable instruments for new efficient regulation policies through econometric tools.

This paper, which is an extended version of [16] is aimed at investigating the impact of different telecommunications-specific and macroeconomic variables over collection rate differentials and traffic imbalance between countries. ${ }^{4}$ They are the core variables addressed by National Regulatory Authorities (NRAs) because of their potential in promoting and increasing telephone traffic. ${ }^{5}$ While telecommunications-specific variables deal with technology, efficiency and efficacy in providing services as well as price levels, macroeconomic data consist, for instance, of trade and touristic flows. An econometric model is developed as an extension of the one proposed by Madden and Savage [8]. This extended model has the main target of including both telecommunicationsspecific and macroeconomic data of 276 couples of countries (processed with

\footnotetext{
${ }^{3}$ The opening of telecommunications market has brought to a radical change in the way of arranging bilateral market costs between countries in the long distance sector [5].

${ }^{4}$ Collection rates are not linked to traffic deficits.

${ }^{5}$ This paper does not aim at explicitly investigating the impact of political (and spatial) directions on telecommunications dynamics. In fact, it focuses on the impact of different telecommunications-specific and macroeconomic variables on clearly mentioned issues (i.e. collection rate differentials and traffic imbalance between countries). Accordingly, though the authors are aware of the relevance of debate as addressed for example in ITU [17], Goodchil and Janelle [18] and Henisz and Zelner [19], they do not intend to perform a qualitative analysis based on the measurement of political constraints.
} 
repetition). ${ }^{6}$ Indeed, the analysis conducted by Madden and Savage [8] is based on bilateral markets between the US and 39 foreign countries. The paper by Madden and Savage examines US international market only analyzing US incoming and outgoing traffic with foreign countries. This is an asymmetrically competitive market for international outgoing calls from the US supplied by $n$ carriers to a foreign country with a monopoly carrier. In this paper a more exhaustive symmetrical analysis is presented comparing incoming and outgoing traffic data referred to 24 countries. Thereafter, Madden and Savage analysis is more incomplete since as market-specific traffic data are unavailable, country dominant carrier's share of outgoing traffic is used to proxy the share of outgoing traffic to US. In the analysis presented in the paper traffic data are more completed and so this assumption has been removed.

Section 1 presents main features of the extended model and shows its variables and equations. Sections 2 and 3 display model, results and some main policy comments. Section 4 provides a comparison between the extended model and the Madden and Savage's one in order to show main differences. Section 5 shows graphs and findings related to the comparison between countries. Final remarks follow.

\section{The model}

This section provides an extension of the model by Madden and Savage [8]. Outgoing traffic from each country distributed among $\mathrm{n}$ carriers is defined as $\mathrm{q}_{\mathrm{oj}}$ and that the total market is $\mathrm{Q}_{\mathrm{o}}=\sum_{\mathrm{j}=1}^{\mathrm{n}} \mathrm{q}_{\mathrm{oj}}$. The profit function $\left(\pi_{\mathrm{j}}\right)$ of the carrier $\mathrm{j}$ is:

$$
\begin{aligned}
\pi_{j}= & q_{O j} P_{O}\left(Q_{O}, Q_{I}, Y_{O}, \Gamma_{O}\right)-C_{O j}\left(q_{O j}, w_{O j}, T e c h_{O}\right)-w_{r O} q_{O j} \\
& +w_{I} q_{I}-C_{I j}\left(q_{I}, w_{O j}, T e c h_{O}\right)
\end{aligned}
$$

where:

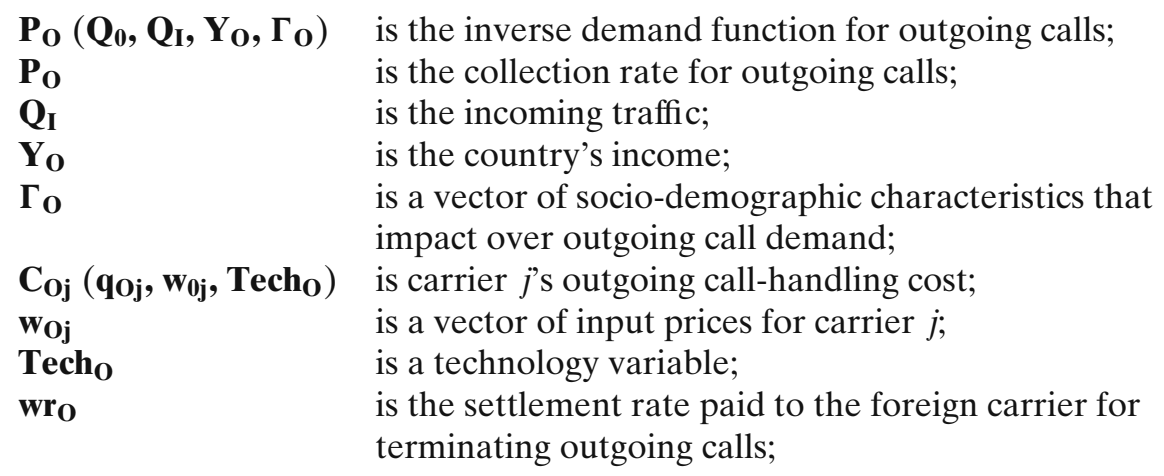

${ }^{6}$ Some of the TLC-specific and macroeconomic data are taken from Beardsley et al. [6] and ITU [20]. 
WrI

is the settlement rate received for terminating incoming calls;

qI is $\mathrm{Q}_{\mathrm{I}} / \mathrm{n}$ ( $\mathrm{n}$ is the number of carriers);

$\mathbf{C}_{\mathbf{I j}}\left(\mathbf{q}_{\mathbf{I}}, \mathbf{w}_{\mathbf{O} \mathbf{j}}, \mathbf{T e c h}_{\mathbf{O}}\right) \quad$ is carrier $j$ 's cost of handling incoming calls.

In order to compare the obtained results with those presented by Madden and Savage [8] we prefer to utilize the same starting propositions. In particular Eq. 1 assumes that competitors are obliged to accept a uniform settlement rate $\left(\mathrm{wr}=\mathrm{wr}_{\mathrm{O}}=\mathrm{wr}_{\mathrm{I}}\right)$ and that aside from billing and marketing costs, the costs of handling outgoing and incoming call should be the same, because transmission costs do not change with the direction of traffic [11]. In the light of this, the first-order necessary condition for carrier $\mathrm{j}$ profit maximization is:

$$
\begin{aligned}
\mathrm{P}_{\mathrm{O}} & +\mathrm{q}_{\mathrm{Oj}}\left[\partial \mathrm{P}_{\mathrm{O}} / \partial \mathrm{q}_{\mathrm{Oj}}+\sum_{\mathrm{k} \neq \mathrm{j}}^{\mathrm{n}}\left(\partial \mathrm{P}_{\mathrm{O}} / \partial \mathrm{q}_{\mathrm{Ok}} * \partial \mathrm{q}_{\mathrm{Ok}} / \partial \mathrm{q}_{\mathrm{Oj}}+\partial \mathrm{P}_{\mathrm{O}} / \partial \mathrm{q}_{\mathrm{I}} * \partial \mathrm{q}_{\mathrm{I}} / \partial \mathrm{q}_{\mathrm{Oj}}\right)\right] \\
& -\mathrm{MC}_{\mathrm{Oj}}\left(\mathrm{q}_{\mathrm{Oj}}, \mathrm{w}_{\mathrm{Oj}}, \operatorname{Tech}_{\mathrm{O}}\right)-\mathrm{wr}+\mathrm{wr} * \partial \mathrm{q}_{\mathrm{I}} / \partial \mathrm{q}_{\mathrm{O}} \\
& -\mathrm{MC}_{\mathrm{Ij}}\left(\mathrm{q}_{\mathrm{Ij}}, \mathrm{w}_{\mathrm{Oj}}, \operatorname{Tech}_{\mathrm{O}}\right) * \partial \mathrm{q}_{\mathrm{I}} / \partial \mathrm{q}_{\mathrm{O}}
\end{aligned}
$$

where both $\mathrm{MC}_{\mathrm{Oj}}\left(\mathrm{q}_{\mathrm{Oj}}, \mathrm{w}_{\mathrm{Oj}}, \mathrm{Tech}_{\mathrm{O}}\right)=\partial \mathrm{C}_{\mathrm{Oj}} / \partial \mathrm{q}_{\mathrm{Oj}}$ and $\mathrm{MC}_{\mathrm{Ij}}\left(\mathrm{q}_{\mathrm{Ij}}, \mathrm{w}_{\mathrm{Oj}}, \mathrm{Tech}_{\mathrm{O}}\right)=$ $\partial \mathrm{C}_{\mathrm{Ij}} / \partial \mathrm{q}_{\mathrm{Ij}}$ indicate in the brackets the strategic behaviour of costs and, moreover, it enlightens the influence that the carrier $j$ 's output has on the international rate. Assuming that incoming cost equals the outgoing cost, Eq. 2 becomes:

$$
\begin{aligned}
\mathrm{P}_{\mathrm{O}} & +\mathrm{q}_{\mathrm{Oj}}\left[\partial \mathrm{P}_{\mathrm{O}} / \partial \mathrm{q}_{\mathrm{Oj}}+\sum_{\mathrm{k} \neq \mathrm{j}}^{\mathrm{n}}\left(\partial \mathrm{P}_{\mathrm{O}} / \partial \mathrm{q}_{\mathrm{Ok}} * \partial \mathrm{q}_{\mathrm{Ok}} / \partial \mathrm{q}_{\mathrm{Oj}}+\partial \mathrm{P}_{\mathrm{O}} / \partial \mathrm{q}_{\mathrm{I}} * \partial \mathrm{q}_{\mathrm{I}} / \partial \mathrm{q}_{\mathrm{Oj}}\right)\right] \\
& =\mathrm{MC}_{\mathrm{Oj}}^{\mathrm{S}}\left(\mathrm{q}_{\mathrm{Oj}}, \mathbf{w}_{\mathrm{Oj}}, \mathrm{Tech}_{\mathrm{O}}, \mathrm{wr}\right)
\end{aligned}
$$

where marginal cost for carrier $\mathrm{j}$ is: $\left[\left(1+\left(\partial \mathrm{q}_{\mathrm{I}} / \partial \mathrm{q}_{\mathrm{O}}\right)\right) * \mathrm{MC}_{\mathrm{Oj}}\left(\mathrm{q}_{\mathrm{Oj}}, \mathrm{w}_{\mathrm{Oj}}, \mathrm{Tech}_{\mathrm{O}}\right)+\right.$ $\left(1-\left(\partial \mathrm{q}_{\mathrm{I}} / \partial \mathrm{q}_{\mathrm{O}}\right) * \mathrm{wr}\right]$. In the case there is no reversion or reciprocity $\left(\left(\partial \mathrm{q}_{\mathrm{I}} / \partial \mathrm{q}_{\mathrm{Oj}}\right)=0\right), \mathrm{MC}_{\mathrm{Oj}}^{\mathrm{S}}$ equals the cost of handling outgoing calls plus the wholesale rate. Conversely, when $\left(\left(\partial \mathrm{q}_{\mathrm{I}} / \partial \mathrm{q}_{\mathrm{Oj}}\right)<0\right)$, the marginal cost of the call decreases as the cost of handling an incoming meanwhile, it rises because it is deeply linked to the reduction of incoming call wholesale rate revenue. Finally, if $\left(\left(\partial \mathrm{q}_{\mathrm{I}} / \partial \mathrm{q}_{\mathrm{Oj}}\right)>0\right)$, the increase in the cost of handling an incoming call is offset by increased incoming-call [8] wholesale rate revenue. Moreover, it is possible to express the supply relation (3) considering that market conduct influences both price and profitability of carrier $j$. It is:

$$
\mathrm{P}_{\mathrm{O}}-\tau_{\mathrm{Oj}} * \mathrm{q}_{\mathrm{Oj}}=\mathrm{MC}_{\mathrm{Oj}}^{\mathrm{S}}\left(\mathrm{q}_{\mathrm{Oj}}, \mathrm{w}_{\mathrm{Oj}}, \mathrm{Tech}_{\mathrm{O}}, \mathrm{wr}\right)
$$


where $\tau_{\mathrm{Oj}}=\left[\mathrm{P}_{\mathrm{O}}-\mathrm{MC}_{\mathrm{Oj}}^{\mathrm{S}}\left(\mathrm{q}_{\mathrm{Oj}}, \mathrm{w}_{\mathrm{Oj}}, \mathrm{Tech}_{\mathrm{O}}, \mathrm{wr}\right)\right] / \mathrm{q}_{\mathrm{Oj}}$ is the ratio of price-cost mark-up to quantity and measures the degree of oligopolistic competition. The relationship between outgoing and incoming traffic, $\mathrm{dq}_{\mathrm{I}} / \mathrm{dq}_{\mathrm{Oj}}$, presupposes that carrier $\mathrm{j}$ has to consider the strategic conduct of both national and foreign carriers. It introduces another expression:

$$
\tau_{\mathrm{Oj}}=\tau_{\mathrm{Oj}}\left(\mathrm{MCI}_{\mathrm{O}}, \text { Comp, Priv }\right)
$$

where $\mathrm{MCI}_{\mathrm{O}}$ represents an index of concentration of outgoing traffic; Comp is the measure of competition in both markets and, finally, Priv is the share of private ownership of carriers operating in the bilateral markets. According to this, supply relation for the average carrier $j$ is:

$$
\mathrm{P}_{\mathrm{O}}=\mathrm{MC}_{\mathrm{Oj}}^{\mathrm{S}}\left(\mathrm{q}_{\mathrm{Oj}}, \mathrm{w}_{\mathrm{Oj}}, \mathrm{Tech}_{\mathrm{O}}, \mathrm{wr}\right)+\tau_{\mathrm{Oj}}\left(\mathrm{MCI}_{\mathrm{O}}, \text { Comp, Priv }\right) * \mathrm{q}_{\mathrm{Oj}}
$$

According to [8], " $\tau_{\mathrm{O}}$ is industry average conduct, and $\tau_{\mathrm{O}}=0$ implies no market power is present. As $\tau_{\mathrm{O}}$ moves away from zero, average carrier conduct is less competitive". Flexibility of adopted model allows estimating affordable empirical data and analysing the reliability of model results. A four equations system has been implemented in order to achieve an affordable estimation of the previous equation. More specifically, two of them are related to the outgoing and incoming supply relations and two of them deal with outgoing and incoming demand equations. As reported by [8], the log-linear system for bilateral market $i$ at time $t$, is:

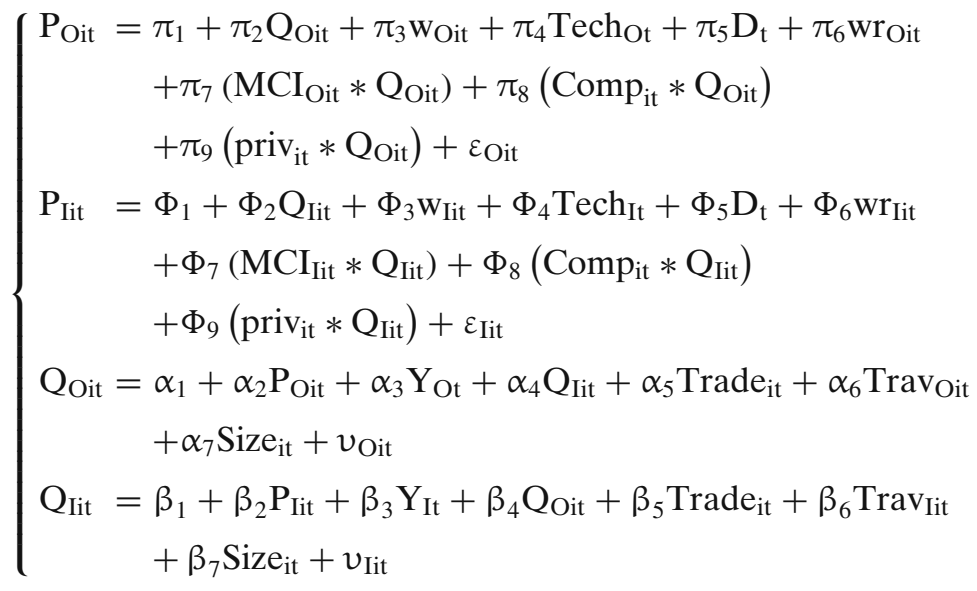

where $\varepsilon_{\text {Oit }}, \varepsilon_{\text {Iit }}, v_{\text {Oit }}$ and $v_{\text {Iit }}$ are disturbance terms.

Before briefly describing empirical results, a Table 1 is presented to sum up differing variables. It shows both the mean and standard deviation for each collected variable (years 2003-2006):

The significance of processed variables deals with the need to investigate both specific aspects of telecommunications worldwide markets and general 
Table 1 Variables description and sample statistics 2003-2006

\begin{tabular}{|c|c|c|c|}
\hline Variable & Definition (measurement units) & Mean & $\mathrm{SD}$ \\
\hline$\overline{\mathrm{P}_{\mathrm{O}}}$ & Per minute retail price for outgoing calls (US\$) & 1.58 & 1.52 \\
\hline $\mathrm{P}_{\mathrm{I}}$ & Per minute retail price for incoming calls (US\$) & 1.59 & 1.51 \\
\hline $\mathrm{Q}_{\mathrm{O}}$ & Outgoing traffic volume (millions of minutes) & 123.93 & 330.54 \\
\hline $\mathrm{Q}_{\mathrm{I}}$ & Incoming traffic volume (millions of minutes) & 125.77 & 332.87 \\
\hline $\mathrm{W}_{\mathrm{O}}$ & Number of mainlines per employee in outgoing market & 52.94 & 14.65 \\
\hline $\mathrm{W}_{\mathrm{I}}$ & Number of mainlines per employee in incoming market & 52.94 & 14.65 \\
\hline $\mathrm{WR}_{\mathrm{O}}$ & Wholesale rate in outgoing market (US\$) & 0.20 & 0.16 \\
\hline $\mathrm{WR}_{\mathrm{I}}$ & Wholesale rate in incoming market (US\$) & 0.20 & 0.16 \\
\hline $\mathrm{TECH}_{\mathrm{O}}$ & ICT Development Index ${ }^{\mathrm{a}}$ of outgoing market & 5.50 & 1.01 \\
\hline $\mathrm{TECH}_{\mathrm{I}}$ & ICT Development Index of incoming market & 5.50 & 1.01 \\
\hline $\mathrm{D}$ & Average distance between countries (kilometres) & $5,687.90$ & $4,677.87$ \\
\hline $\mathrm{MCI}_{\mathrm{O}}$ & Incumbent's market share in outgoing market (percentage) & 34.98 & 4.98 \\
\hline $\mathrm{MCI}_{\mathrm{I}}$ & Incumbent's market share in incoming market (percentage) & 16.20 & 2.32 \\
\hline COMP & $\begin{array}{l}\text { Number of national competitors in outgoing and } \\
\text { incoming markets }\end{array}$ & 10.21 & 2.82 \\
\hline PRIV & $\begin{array}{l}\text { Public ownership in telecommunication companies } \\
\text { (percentage) }\end{array}$ & 1.61 & 0.33 \\
\hline $\mathrm{Y}_{\mathrm{O}}$ & Gross Domestic Product (millions of dollars) & $8,315.85$ & 260.11 \\
\hline $\mathrm{Y}_{\mathrm{I}}$ & Gross Domestic Product (millions of dollars) & $8,121.55$ & 190.19 \\
\hline TRAV $_{\mathrm{O}}$ & $\begin{array}{l}\text { Number of travelling tourists from outgoing market } \\
\text { (millions) }\end{array}$ & 5.78 & 0.99 \\
\hline TRAV $_{I}$ & $\begin{array}{l}\text { Number of travelling tourists from incoming market } \\
\text { (millions) }\end{array}$ & 4.45 & 1.21 \\
\hline TRADE $_{O}$ & $\begin{array}{l}\text { Export from outgoing to incoming market } \\
\text { (millions of dollars) }\end{array}$ & $6,206.98$ & $1,732.11$ \\
\hline TRADE $_{I}$ & $\begin{array}{l}\text { Export from incoming to outgoing market } \\
\text { (millions of dollars) }\end{array}$ & $6,197.34$ & $1,699.21$ \\
\hline SIZE & Population of outgoing $*$ population of incoming country & $1,827.99$ & $3,011.87$ \\
\hline
\end{tabular}

aThe "ICT Development Index" has been developed by International Telecommunication Union [20]

macroeconomic conditions affecting countries. As a consequence, on one hand, the amount of incoming and outgoing traffic, wholesale rates, per minute retail prices, number of competitors and degree of privatisation provide analysts and researchers with useful and suggestive information about the degree of market competition and concentration, the largeness and attractivity of the specific market. On the other hand, data as GDP and trade flows strongly contribute to justify the interest of telecommunications companies in investing and expanding in worldwide markets. The Information \& Communications Technology (ICT) Development Index (IDI) has been used in this paper as the technological degree of telecommunication network. This index combines 11 indicators into a single measure that can be used as a benchmarking tool globally, regionally and at country level. It is related to ICT access (Fixed telephone lines for 100 inhabitants, mobile cellular telephone subscription per 100 inhabitants, international internet bandwidth per internet user, proportion of households with a computer and proportion of household with internet access at home), ICT use (internet users per 100 inhabitants, fixed broadband internet subscribers per 100 inhabitants and mobile broadband subscribers per 
100 inhabitants) and ICT skills (adult literacy rate, secondary gross enrolment ratio and tertiary gross enrolment ratio). This index provided by International Telecommunications Union compares developments in information and communication technologies in 154 countries over a 5-year period from 2002 to 2007.

\section{Results}

The dataset used is based on annual data for 552 bilateral markets for the period 2003 through 2006. Of the 24 countries contained in the sample, four are Asian-Pacific (Australia, Korea, Singapore and Japan), seventeen are European (Austria, Belgium, Czech Republic, Denmark, Finland, France, Germany, Ireland, Italy, Netherlands, Norway, Portugal, Spain, Sweden, Switzerland, Turkey and UK) and three American (Canada, Mexico e USA). Although International VoIP traffic grew in the last decade with no sign of abating (about $35 \%$ per year), in our simulation VoIP is not considered for two reasons: (a) the majority of VoIP traffic is terminated in developing countries not analyzed in our sample whose telecommunications markets have not fully or just recently liberalized and where international call termination rates remain relatively high (b) the aggregation level of switched and VoIP traffic data are different, VoIP traffic are not available at bilateral level but only at more aggregated level. The variables are estimated by three stage least squares (3SLS); $R^{2}$ values are satisfactory to test the model. All estimated coefficients denote significance at the $5 \%$ level. Three stage least squares estimates are obtained by first estimating a set of nonlinear (or linear) equations with crossequation constraints imposed, but with a diagonal covariance matrix of the disturbances across equations. This is the constrained two stage least squares estimator. The parameter estimates thus obtained are used to form a consistent estimate of the covariance matrix of the disturbances, which is then used as a weighting matrix when the model is re-estimated to obtain new values of the parameters. Simulations are run with RATS $®$ econometric software and correlation analysis shows that variables MCI and COMP are not significantly correlated. Before showing regression results, two aspects are made clear. First of all, each variable has a statistically significance in spite of values just strictly over or below zero. In this way, an extremely low coefficient does not impinge on the consistency of results because of the relevance of information contained in its own sign (positive or negative). Secondly, by logical deductions, some expectations and assumptions about evidences are formulated:

- $\partial \mathrm{P} / \partial \mathrm{Q} \geq 0$ implies that an increasing of the supply by carriers brings to a growing collection rate;

- $\partial \mathrm{P} / \partial \mathrm{w} \leq 0$ indicates that international telephone tariffs are expected to decrease as labour productivity goes arises;

- $\partial \mathrm{P} / \partial \mathrm{Tech}$ is difficult to pre-determine. Indeed, growing efficiency can reflect into a progressive decreasing of collection rates but, at the same 
time, the better quality of service can induce carriers to modulate tariffs with sensible increasing;

- $\partial \mathrm{P} / \partial \mathrm{D} \geq 0$ deals with the positive relation between distance and collection rates (a call from the USA to Australia costs, on the average, more than a call from the USA to Canada);

- $\partial \mathrm{P} / \partial \mathrm{WR} \geq 0$ supports the expectation that access to international networks deeply affects costs supported by carriers and it reflects the positive relation with collection rates;

- $\partial \mathrm{P} / \partial(\mathrm{MCI}) \geq 0$ reflects, as stated by Madden and Savage [8] that "the ability of carriers to set collection rates above cost is assumed positively related to market concentration";

- $\partial \mathrm{P} / \partial$ Comp $\leq 0$ indicates that there is a negative relation between increased rivalry in originating and destination markets and the level of collection rates;

- $\partial \mathrm{P} / \partial$ Priv $\leq 0$ shows a negative relation between the private share in the equity of carrier and collection rates applied. More specifically, the higher is the private ownership for the foreign carrier, the lower is the outgoing/ incoming collection rate;

- $\partial \mathrm{PO} / \partial \mathrm{wrO}+\partial \mathrm{QI} / \partial \mathrm{QO}=\partial \mathrm{PI} / \partial \mathrm{wrI}+\partial \mathrm{QO} / \partial \mathrm{QI}=1$ implies the restriction that incoming and outgoing transmission cost are equal.

Starting from such expected results and according to results shown in Table 2, some main comments about the estimation of coefficients in the $\mathrm{P}_{\mathrm{O}}$ equation follow.

- The coefficient of $\mathrm{WR}_{\mathrm{O}}$ is largely positive. The elasticity of final price depending on the variation of wholesale tariff is positive. Because tariffs applied to final customers are influenced by the wholesales, by decreasing the wholesale rate of $30 \%$ the final tariff decreases of about $4 \%$;

- The coefficient D is positive but extremely low. Technology has made distance quite irrelevant in tariff determining. Tech ${ }_{O}$ describes the technological degree of the telecommunication network. The positive coefficient could be intended as an agreement among companies to improve the network through tariffs adjustment.

Table 2 The estimation of coefficients in the $\mathrm{P}_{\mathrm{O}}$ equation

\begin{tabular}{lcll}
\hline Variable & \multicolumn{2}{c}{ 3SLS estimates } & \multicolumn{2}{l}{ Dependent variable: } \\
\cline { 2 - 4 } & Coefficient & Standard error & $\mathrm{P}_{\mathrm{O}}$ \\
\hline Constant & 5.238312 & 0.859209 & $R^{2}=0.8114$ \\
$\mathrm{Q}_{\mathrm{O}}$ & 0.004191 & 0.001008 & \\
$\mathrm{~W}_{\mathrm{O}}$ & -0.409951 & 0.118345 & \\
$\mathrm{Tech}_{\mathrm{O}}$ & 0.298372 & 1.827693 & \\
$\mathrm{WR}_{\mathrm{O}}$ & 0.3677109 & 0.022851 & \\
$\mathrm{D}$ & 0.000121 & 0.000011 & \\
$\mathrm{MCI} * \mathrm{Q}_{\mathrm{O}}$ & 0.103563 & 0.000788 & \\
Comp* & -0.137074 & 0.000035 & \\
Priv $* \mathrm{Q}_{\mathrm{O}}$ & -0.100325 & 0.000331 & \\
\hline
\end{tabular}


- The value of Comp indicates that the higher is the number of competing companies the lower is the level of tariffs. However, a pre-requisite is the existence of competition in every bilateral market. Accordingly, a bilateral market with a regulated and a deregulated market attempts to traffic imbalances and strong divergences in tariffs level.

- Priv indicates the degree of privatization of telecommunications companies. As in the case of Comp variable, the higher the level of privatization the lower the level of tariffs.

- The coefficient $\mathrm{W}_{\mathrm{O}}$ is a measure of company's efficiency. It is calculated by fixed lines out of the number of employees. The negative sign means that the carrier could decrease tariffs by a reduction of costs (e.g. diminishing the number of employees).

- Finally, MCI is a measure of market concentration. Its positive value indicates that the more the market is concentrated the higher is the level of tariffs. As a consequence, a market share reduction of $1 \%$ of the market leader could lead to a decrease of about $0.15 \%$ of tariffs.

Main comments and results (Table 3 ) of the $\mathrm{P}_{\mathrm{I}}$ equation follow.

- The coefficient of $\mathrm{WR}_{\mathrm{I}}$ is largely positive. Accordingly, a decrease in wholesale rate leads to a price reduction. By decreasing the wholesale rate of $25 \%$ the final tariff decreases of about $5 \%$;

- Coefficient D is slightly positive. Because of high-tech features of telecommunications network, distance does not affect very much the level of tariffs.

In this analysis, it is quite insignificant the negative sign of Tech variable. As already stated, the sign of $\mathrm{dP} / \mathrm{dTech}$ is always difficult to pre-determine. In fact, grater technology and digitalization suggest lower collection rates (per minute retail price) through increased efficiency; however, increased technology and digitalization may lead to improved service quality and higher prices. In our simulations percent technology picks up a strong positive coefficient (carriers raise prices to recover investment costs) in the outgoing equations and a quite insignificant one for the incoming. The obtained results follow those obtained by Madden and Savage in the starting model ( 0.684 and -0.023$)$. This

Table 3 The estimation of coefficients in the $\mathrm{P}_{\mathrm{I}}$ equation

\begin{tabular}{lrll}
\hline Variable & \multicolumn{2}{l}{ 3SLS estimates } & Dependent variable: \\
\cline { 2 - 3 } & Coefficient & Standard error & $\mathrm{P}_{\mathrm{I}}$ \\
\hline Constant & 6.435301 & 0.860123 & $R^{2}=0.7341$ \\
$\mathrm{Q}_{\mathrm{I}}$ & -0.201855 & 0.000964 & \\
$\mathrm{~W}_{\mathrm{I}}$ & -0.112549 & 0.003638 & \\
Tech $_{\mathrm{I}}$ & -0.059097 & 0.189581 & \\
$\mathrm{WR}_{\mathrm{I}}$ & 0.761232 & 0.014176 & \\
$\mathrm{D}$ & 0.001011 & 0.000007 & \\
$\mathrm{MCI} * \mathrm{Q}_{\mathrm{I}}$ & 0.603332 & 0.000747 & \\
Comp*Q & -0.200051 & 0.000034 & \\
Priv $* \mathrm{Q}_{\mathrm{I}}$ & -0.091366 & 0.000333 & \\
\hline
\end{tabular}


puzzling result for incoming equation, already reported by Einhorn [1], implies a percent increase in the technological index leads to a $0.059 \%$ weak reduction in collection rates for incoming calls. The obtained result follows that obtained by Madden and Savage in the starting model $(-0.023)$.

- Comp variable is negative. In a bilateral market, the final tariff is strongly influenced by market structure of incoming country. A low concentrated incoming market corresponds to a general lower level of final prices.

\section{A comparison with the Madden and Savage's model}

As shown before, the dataset used is based on annual data for 552 bilateral markets for the period 2003-2006. On the opposite, the original model by Madden and Savage referred to about 40 bilateral markets for the period 1991-1994. Such an extension implies the willingness of providing a detailed and skilled model that could be of a certain importance in telecommunications policy. Detailed comparisons between models follow:

- the Madden and Savage's model considers only US bilateral markets (i.e. USA is always present as a part of the bilateral market). Conversely, the extended model is based on bilateral markets of 24 worldwide countries.

- Madden and Savage's model investigated telecommunications markets of the first 1990s. Accordingly, it considered the settlement rate, a tariff imposed by the carrier of the incoming country to every foreign carrier who wanted to terminate a call in its country. It was a system mainly based on bilateral agreements among monopolists. On the opposite, the extended

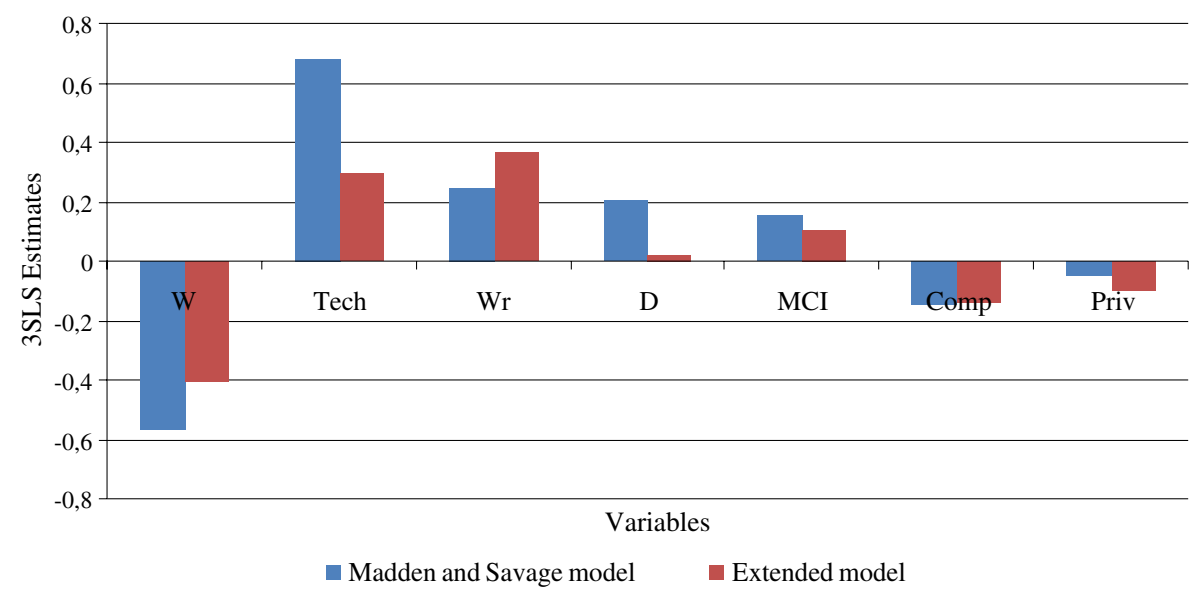

Fig. 2 A comparison of the estimation of coefficients in the PO equation 


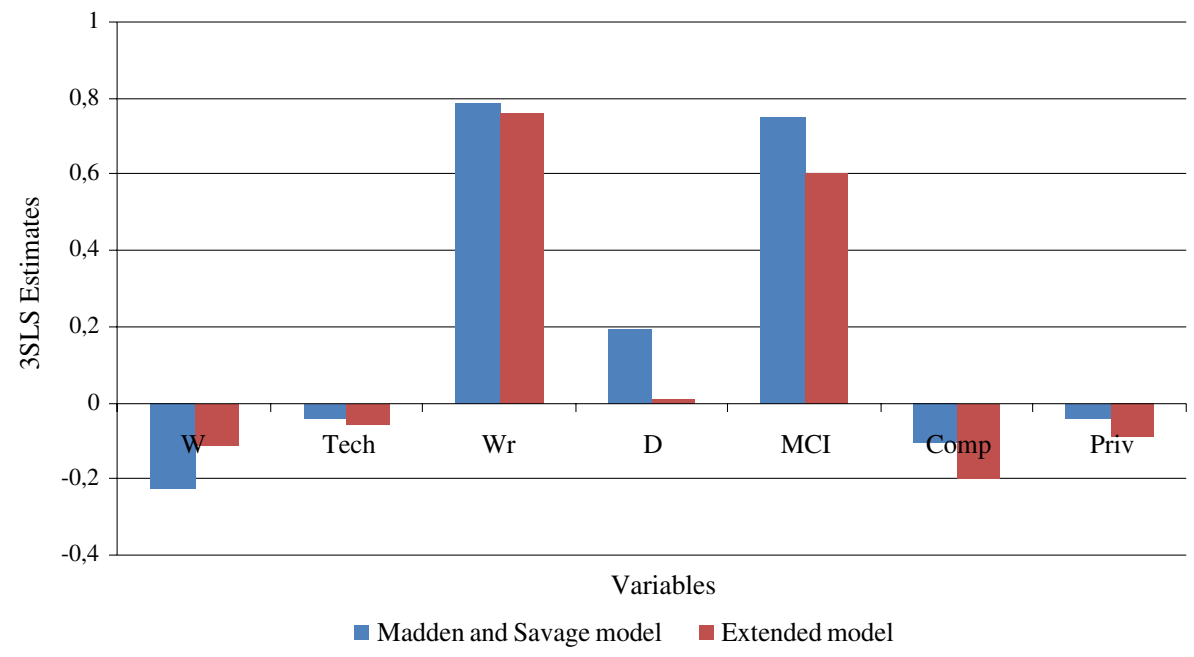

Fig. 3 A comparison of the estimation of coefficients in the $\mathrm{P}_{\mathrm{I}}$ equation

model refers to the wholesale rate. It is a tariff that is proper to liberalized markets.

- The variable Trade has been added to the Madden and Savage's model. Thereafter, some variables have been substituted with some more appropriate to competition in liberalized markets (e.g. WR). However, comparing similar variables in the both of the models, a couple of graphics can be drawn (Figs. 2 and 3).

\section{Analysis of main countries}

Within the analysis of the all 552 bilateral markets, it is possible to investigate the value of certain variables in differing countries. More specifically, Comp, Priv, Tech, MCI and WR variables present specific trends in each of the considered countries. If investigated both Comp and Priv variables in a dispersion graph, it can be underlined the relationship between coefficients describing market structure (Fig. 4).

In the bottom left part of the graph, extremely low values of Priv and Comp variables indicate that UK, USA and Canada are characterized by highly developed market structures. Early liberalization processes and low market concentration have led to strong competition. On the opposite, in the upper right area of the graph, high values of Priv and Comp are for countries with a slow degree of liberalization. Czech Republic, Mexico and Turkey are some of the most significant example in this way. Market concentration is still high and market is now progressively opening to competition. Other countries (e.g. Italy, Germany and Spain) are great examples of markets where liberalization 


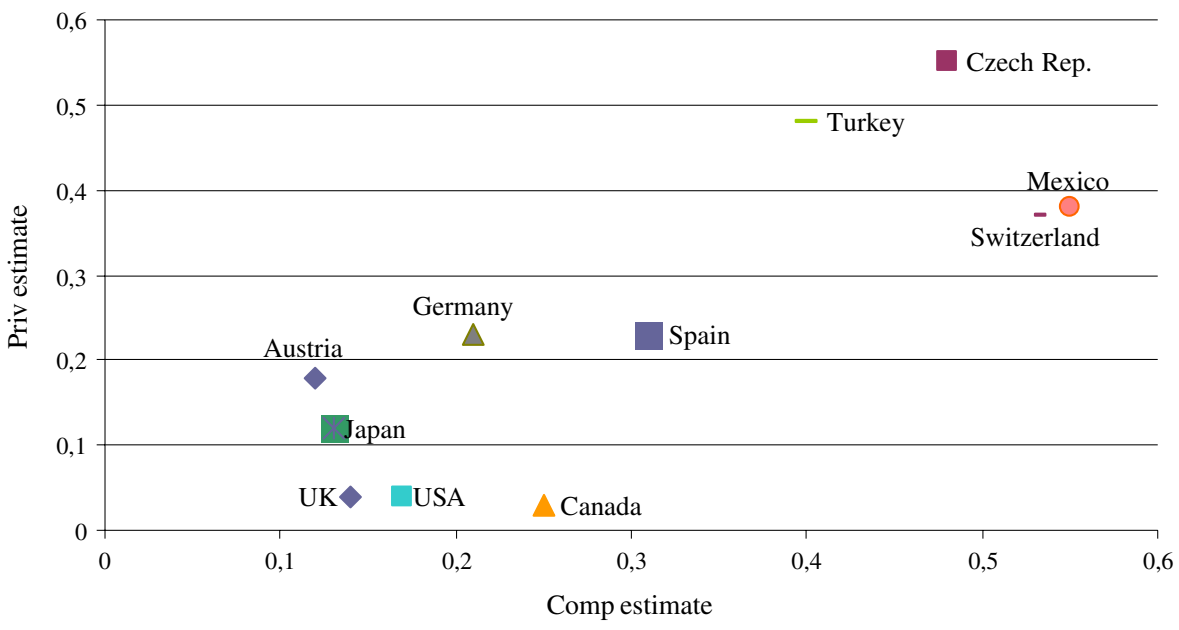

Fig. 4 Comp and Priv in main countries in absolute values

and competition are successfully applied but market maturity is still lower than that of UK and USA.

\section{Final remarks}

The paper analyzed determinants of pricing in international telephone service markets. An extension of the econometric model by Madden and Savage [8] was used to grasp the impact of different telecommunications-specific and macroeconomic variables on collection rate differentials and traffic imbalance between countries. The importance of the approach of the paper relies on possible telecommunications policy applications. In fact, Priv, Comp, Tech, D, WR and MCI all contribute to describe market trends and investigate future competitive developments in the worldwide fixed telephony sector. Coefficients of variable D assume low values for the scarce significance of distance. On the opposite, Comp and Priv are great indicators of the stateof-the-art of liberalization and market openness.

Finally, it has to be underlined that in the analysis of US bilateral markets, Madden and Savage wished a reform from scratch of interconnection prices that were one of the main causes of traffic imbalance. However, after liberalization in many countries, USA still presents a prevalence of outgoing traffic. This is due to wholesale rates. They act as a bottleneck because it decreased more than the final price. Possible future solutions rely on Internet technology and its applications (e.g. Voice on Internet Provider).

Acknowledgements A previous version of this paper has been presented at the CTTE 2007 Conference in Helsinki and it was already assigned of the reference DOI:10.1109/CTTE.2007.4389900. Accordingly, the authors are grateful to Conference participants as well as Journal Editor and 
reviewers, who provided their valuable comments to improve this work. The Italian Ministry of University and Research (MIUR)—under PRIN 2005, Project number 2005098172_003supported this work.

Open Access This article is distributed under the terms of the Creative Commons Attribution Noncommercial License which permits any noncommercial use, distribution, and reproduction in any medium, provided the original author(s) and source are credited.

\section{References}

1. Einhorn, M. A. (2002). International telephony: A review of the literature. Information Economics and Policy, 14, 51-73.

2. Cricelli, L., Gastaldi, M., \& Levialdi, N. (2001). Strategic behaviours in international telecommunications system. International Journal of Production Economics, 69, 141-149.

3. TeleGeography Inc. (2008). TeleGeography 2008. Washington: TeleGeography Inc.

4. Cricelli, L., Di Pillo, F., Gastaldi, M., \& Levialdi, N. (2005). Wholesale competition in international telecommunications system. Networks and Spatial Economics, 5(3), 261-277.

5. Galbi, D. A. (1998). Distinctive arrangements for international interconnection? Telecommunications Policy, 22(11), 945-951.

6. Beardsley, S., Enriquez, L., \& Garcia, J. C. (2004). A new route for telecom deregulation. The McKinsey Quarterly, 3. Available at http://www.mckinseyquarterly.com/article_print.aspx? $\mathrm{L} 2=22 \& \mathrm{~L} 3=0 \& \mathrm{ar}=1437$.

7. Mason, R. (1998). Internet telephony and the international accounting rate system. Telecommunications Policy, 22(11), 931-944.

8. Madden, G., \& Savage, S. J. (2000). Market structure, competition, and pricing in United States international telephone service markets. The Review of Economics and Statistics, l.82(2), 291-296.

9. Alleman, J., Madden, G., \& Savage, S. J. (2000). Trade imbalance in international message telephone services. Applied Economics, 32, 1311-1321.

10. Cave, M., \& Waverman, L. (1998). The future of international settlements. Telecommunications Policy, 22(11), 883-898.

11. Alleman, J., \& Sorce, B. (1997). International settlements: A time for change. In Proceeding of the global networking 1997 conference, June 15-17, Calgary, Canada.

12. Wright, J. (1999). International telecommunications, settlement rates, and the FCC. Journal of Regulatory Economics, 15, 1-24.

13. Kelly, T. (1997). Is there life for accounting rate system? Telegeography, 1997/98, 33-38.

14. Gastaldi, M., Levialdi, N., \& Nucciarelli, A. (2008). International telecommunications imbalances: An empirical analysis. International Journal of Logistic Economics and Globalization, 2(1), 141-159.

15. ITU (1999). Direction of traffic. Trading telecom minutes. Geneva: International Telecommunications Union.

16. Nucciarelli, A., Gastaldi, M., \& Levialdi, N. (2007). Asymmetric competition and collection rates differentials: Determinants of prices in international telephone service markets. In CTTE conference 2007, June 14-15, 2007, Helsinki, Finland. doi:10.1109/CTTE.2007.4389900.

17. Goodchil, M. F., \& Janelle, D. G. (2004). Spatial integrated social science. New York: Oxford University Press.

18. Henisz, W. J., \& Zelner, B. A. (2001). The institutional environment for telecommunications investment. Journal of Economics \& Management Strategy, 10(1), 123-147.

19. Ghosh, A., \& Meagher, K. (2004). Political economy of infrastructure investment: A spatial approach. In North American Econometric Society Summer Meetings at Brown University, Providence, USA.

20. ITU (2009). ICT development index. http://www.itu.int/ITU-D/ict/publications/idi/2009/index. html. Accessed 16 April 2009. 